\title{
Prevention of chronic gastritis by fermented milks made with exopolysaccharide-producing Streptococcus thermophilus strains
}

\author{
C. Rodríguez, ${ }^{*}$ M. Medici, ${ }^{*}$ A. V. Rodríguez, ${ }^{*}$ F. Mozzi, ${ }^{*}$ and G. Font de Valdez ${ }^{*} \dagger^{1}$ \\ ${ }^{*}$ Centro de Referencia para Lactobacilos (CERELA)-CONICET, Chacabuco 145, San Miguel de Tucumán, 4000 Tucumán, Argentina \\ †Cátedra Microbiología Superior, Facultad de Bioquímica, Química y Farmacia, Universidad Nacional de Tucumán, Ayacucho 491, \\ San Miguel de Tucumán, 4000 Tucumán, Argentina
}

\section{ABSTRACT}

Acetyl-salicylic acid (ASA) is a nonsteroidal antiinflammatory/analgesic drug, which may cause gastritis or stomach ulcers if intensively employed. Exopolysaccharide (EPS)-producing lactic acid bacteria have been claimed to induce immunostimulatory/antiulcer effects in the host. This study investigated the potential preventive effect of fermented milks (FM) with EPS-producing Streptococcus thermophilus strains (CRL 1190 and CRL 804) on an in vivo model of chronic gastritis. Fermented milks $\left(2 \mathrm{EPS}^{+}\right.$and $1 \mathrm{EPS}^{-}$, separately) were fed to BALB/c mice for $7 \mathrm{~d}$ before inducing gastritis with ASA (400 mg/kg of body weight per day for 10 $\mathrm{d}$; gastritis group, $\mathrm{n}=5$ ). Appropriate control groups (ASA administered but not given $\mathrm{FM}, \mathrm{n}=5$; and ASA not administered but given FM) were included in this study. Gastric inflammatory activity was evaluated through the stomach's histology and the number of $\mathrm{IFN}^{+}$and IL- $10^{+}$cytokine-producing cells in the gastric mucosa. Only mice preventively treated with the EPS-producing Strep. thermophilus CRL 1190 FM and later administered ASA did not develop gastritis, showing a conserved gastric mucosa structure similar to those of healthy mice. A marked decrease of IFN $\gamma^{+}$and increase of IL- $10^{+}$-producing cells compared with the gastritis group mice were observed. Purified EPS from Strep. thermophilus CRL 1190 resuspended in autoclaved milk was also effective for gastritis prevention. The EPS-protein interaction might be responsible for the observed gastroprotective effect; such interactions may be affected by industrial manufacturing conditions. The results indicate that the FM with Strep. thermophilus CRL 1190 or its EPS could be used in novel functional foods for preventing chronic gastritis.

Key words: lactic acid bacteria, exopolysaccharide, gastritis, preventive effect

Received September 17, 2008

Accepted December 30, 2008.

${ }^{1}$ Corresponding author: gfont@cerela.org.ar

\section{INTRODUCTION}

Acetyl-salicylic acid (ASA) is a nonsteroidal antiinflammatory drug used worldwide as an analgesic, antiinflammatory, and antipyretic agent, as well as to prevent cardiovascular thrombotic events. Nonsteroidal antiinflammatory drug administration is associated with gastrointestinal complications ranging from dyspepsia and abdominal pain to gastric ulcers. Gastric lesions are caused by a direct toxic effect on gastric epithelial cells, producing inhibition of enzymes, a reduction in mucosal blood flow (Ashley et al., 1985), adherence of leukocytes to the vascular endothelium, and the amplification of the inflammatory process by expression of pro-inflammatory cytokines (Lamarque, 2004). It also leads to diminished bicarbonate and mucus secretion with decrease in hydrophobicity of the mucus gel layer (Wallace, 1997).

The mucosal immune system of mammals consists of an integrated network of tissues, lymphoid, and mucous membrane-associated cells and effector molecules that are involved in the host protection. Among the effector molecules, cytokines that can be produced by multiple cell types (e.g., lymphocytes, monocytes, macrophage, mast cells, and endothelial and epithelial cells) mediate the immune response (Perdigón et al., 2004). The type of cytokine released by the immune cells is associated to the type of response obtained, which can be T-helper 1 immunogenic, T-helper 2 humoral or tolerogenic immune, or only an inflammatory response.

Functional foods are any fresh or processed foods claimed to have a health-promoting or disease-preventing property beyond the basic nutritional function of supplying nutrients. The functional food industry has tremendously increased in recent years because of the consumer's demand for attractive and healthy foods. Functional food ingredients include probiotics, prebiotics, synbiotics, vitamins, and minerals, and are found in diverse types of food products such as dairy products, sports drinks, and baby foods (Sanders, 1998; Stanton et al., 2005).

Probiotics are defined as "live microorganisms which when consumed in adequate numbers confer a health 
benefit on the host" (FAO/WHO, 2001). Consumption of probiotic products, particularly those containing lactic acid bacteria (LAB), can have a variety of beneficial effects including enhanced immune response, balance of the colonic microbiota (Kalliomäki et al., 2008), anticarcinogenic activity (Burns and Rowland, 2000), growth inhibition of enteropathogens (Drago et al., 1997; Collado et al., 2005), control of Clostridium difficile-induced colitis (Plummer et al., 2004), and prevention and treatment of gastric ulcers and inflammation related to Helicobacter pylori (Johnson-Henry et al., 2004; Sgouras et al., 2004).

Certain LAB produce exopolysaccharides (EPS), either capsular polysaccharides (CPS) that are tightly associated with the cell surface or slime EPS that are secreted into the extracellular environment (De Vuyst and Degeest, 1999; Vaningelgem et al., 2004; Mozzi et al., 2006). These biopolymers are long-chain polysaccharides consisting of branched repeating units of sugars or sugar derivatives, composed of one type of monosaccharide (homopolysaccharides) or formed by repeating units of 2 or more types of monosaccharides (heteropolysaccharides, HePS; De Vuyst and Degeest, 1999). A large number of HePS from LAB exist, differing in their chemical characteristics, yields, and functionalities (Vaningelgem et al., 2004; Mozzi et al., 2006). These EPS have important technological properties and are widely used in the food industry to improve the rheology of fermented products (De Vuyst and Degeest, 1999; Ruas-Madiedo and De los Reyes-Gavilán, 2005). Although their biological role is not well understood, EPS are believed to be involved in bacterial protection (Roberts, 1996). It has also been suggested that EPS may have beneficial effects for human health, such as cholesterol-lowering (Nakajima et al., 1992), antitumoral (Kitazawa et al., 1991), and antiulcer (Nagaoka et al., 1994) activities, which might be related to their chemical structures (Ruas-Madiedo et al., 2002). In this respect, Nagaoka et al. (1994) reported certain antiulcer effects of EPS produced by bifidobacteria, lactobacilli, and streptococci strains. However, the protection of the gastric epithelium by EPS-producing LAB has not yet been described in detail.

The aim of this work was to assess the potential antigastritis effect of fermented milks (FM) with EPSproducing Streptococcus thermophilus strains using a murine model of chronic gastritis induced by ASA.

\section{MATERIALS AND METHODS}

Animal protocols used in this study were approved by the Ethical Committee for Animal Care of the Centro de Referencia para Lactobacilos (CERELA, Tucumán, Argentina).

\section{Microorganisms and Culture Conditions}

Two EPS-producing $\left(\mathbf{E P S}^{+}\right)$streptococcus strains, Strep. thermophilus CRL 1190 and Strep. thermophilus CRL 804, and 1 EPS-negative (EPS ${ }^{-}$) strain, Strep. thermophilus CRL 728, were used in this study. These strains belong to the Culture Collection of CERELA. The EPS production and the polymer structural characteristics (chemical composition and molecular mass, MM) were previously determined (Mozzi et al., 2006) and are listed in Table 1. The EPS-producing Strep. thermophilus strains were selected based on the physicochemical properties of their polysaccharides and for displaying no secondary effects such as bacterial translocation (liver and spleen). In this regard, possible side effects were previously assayed in vivo by oral administration of these strains. All strains were cultured $(1 \%$, vol/vol, inoculum) in LAPTg broth [peptone, $1.5 \%$ (wt/vol); tryptone, $1.0 \%$ (wt/vol), yeast extract, $1.0 \%$ (wt/vol); glucose, $1.0 \%$ (wt/vol), and polysorbate $80,0.1 \%(\mathrm{vol} / \mathrm{vol})]$ and subcultured at least twice in reconstituted skim milk (RSM; $10 \%$ wt/vol) just before experimental use. The strains were kept at $-20^{\circ} \mathrm{C}$ in RSM containing 10\% (vol/vol) glycerol, $1 \%$ (wt/vol) glucose, and $0.5 \%$ (wt/vol) yeast extract.

\section{Animals}

Six-week-old BALB/c male mice (25-30 g) were obtained from a closed colony kept at the animal facilities of CERELA and maintained in a room with a 12-h light/dark cycle at $20 \pm 2^{\circ} \mathrm{C}$. The mice were individually housed in cages $(20 \times 30 \times 15 \mathrm{~cm})$ with a litter tray of $20 \times 30 \times 6 \mathrm{~cm}$, and were allowed to have free access to a conventional balanced diet and water ad libitum. All mice received no food for $24 \mathrm{~h}$ before the experiments but had free access to water.

\section{Induction of In Vivo Gastritis by ASA}

The BALB/c mice were divided into the following groups $(\mathrm{n}=5$ each): the gastritis group, $(\mathbf{G}$; ASA administered) group and the healthy mice (H; ASA not administered) group. Chronic gastritis was induced in the mice in group $\mathrm{G}$ by oral administration of ASA (Bayer SA Munro, Buenos Aires, Argentina) in the water supply at an approximate daily dose of $400 \mathrm{mg} / \mathrm{kg}$ of BW per d for 10 d (Wallace et al., 1995; Canadian Council on Animal Care, 1998). This dose corresponds to twice the analgesic dose for mice and was applied to develop gastritis in a shorter experimental time. Healthy mice received drinking water without ASA during the same time. After the experimental period (d 11), mice were killed by cervical dislocation and weighed. Stomachs 
Table 1. Growth and exopolysaccharide (EPS) production by Streptococcus thermophilus strains in milk cultures and characteristics of their polymers

\begin{tabular}{|c|c|c|c|c|c|c|c|}
\hline $\begin{array}{l}\text { S. thermophilus } \\
\text { strain }\end{array}$ & $\begin{array}{l}\text { Viability } \\
(\mathrm{cfu} / \mathrm{mL})\end{array}$ & $\mathrm{pH}$ & $\mathrm{CPS}^{1}$ & Ropiness & $\begin{array}{c}\text { EPS } \\
\text { production }\end{array}$ & $\begin{array}{l}\text { Molecular } \\
\text { mass (kDa) }\end{array}$ & $\begin{array}{c}\text { Monomer }^{3} \\
\text { composition }\end{array}$ \\
\hline CRL 804 & $2.0 \times 10^{8}$ & 4.50 & - & - & 166 & 95 & Gal-Rha \\
\hline CRL 1190 & $1.0 \times 10^{8}$ & 4.50 & + & + & 39 & 1,782 & Glc-Gal \\
\hline
\end{tabular}

${ }^{1}$ Capsular polysaccharide.

${ }^{2}$ Exopolysaccharide production in reconstituted skim milk (10\% wt/vol) expressed as polymer dry mass (mg/L). Inoculum used (1\% vol/vol); fermentation conditions incubation at $37^{\circ} \mathrm{C}$ for $16 \mathrm{~h}$. Exopolysaccharide measurements were carried out in duplicate independent experiments and values shown are the mean.

${ }^{3}$ Monomer composition: Gal = galactose; Rha $=$ rhamnose; Glc $=$ glucose (Mozzi et al., 2006).

were aseptically removed, weighed, and rinsed several times with saline solution and used for determining the gastric inflammatory activity as described below.

\section{Gastric Inflammatory Activity}

Microscopic and Histopathologic Analysis of Gastric Samples. Stomachs were fixed in 10\% (vol/ vol) paraformaldehyde in 0.1 M PBS (pH 7.0) and embedded in paraffin following the Saint-Marie technique (Saint-Marie, 1962). Three serial paraffin sections (4 $\mu \mathrm{m})$ of each sample were cut from each specimen and stained with hematoxylin-eosin followed by light microscopy examination (Leica DM LS2, Wetzlar, Germany). The pathologic characteristics and the degree of inflammation of the gastric mucosa were assessed according to the updated Sydney system (Dixon et al., 1996) by microscopic observation without knowledge of the experimental groups and expressed as follows:

- normal appearance of scattered mononuclear cells on the lamina propria (the same degree as healthy control mice), none $=$ score 0

- mild infiltration of mononuclear cells in the lamina propria and the submucosa, and no erosion in the epithelium, mild $=$ score 1

- moderate infiltration of mononuclear cells in the lamina propria and the submucosa, and no erosion in the epithelium, moderate $=$ score 2 , and

- severe infiltration of mononuclear cells in the lamina propria and the submucosa, and erosion in some parts of the epithelium, severe $=$ score 3 .

Determination of the Number of IFN- $\gamma^{+}$and IL-10 $0^{+}$Producing Cells in the Gastric Mucosa by Indirect Immunofluorescence Assay. Histological slices of the antral and corpus regions of the stomach, processed as described earlier, were deparaffinized and rehydrated in a graded series of ethanol. After incubation at room temperature for $30 \mathrm{~min}$ in $1 \%$ (wt/vol) blocking solution of BSA (Sigma Chemical
Co., St. Louis, MO), histological slices were incubated at $37^{\circ} \mathrm{C}$ for $60 \mathrm{~min}$ with rabbit anti-mouse IFN- $\gamma$ or IL-10 (Peprotech Inc., Rocky Hill, NJ) polyclonal antibodies. Then, the sections were washed twice with saline solution and treated with a 1/10 dilution of a goat anti-rabbit antibody conjugated with fluorescein isothiocyanate (Jackson ImmunoResearch Inc., West Grove, PA) at $37^{\circ} \mathrm{C}$ for $45 \mathrm{~min}$; washed again with saline solution and examined with a fluorescent light microscope (Leica DM LS2). Results were expressed as the number of IFN- $\gamma$ and IL-10-producing cells (fluorescent cells) per 10 fields (magnification 1,000×; Vinderola et al., 2004). Data were obtained from counting 30 fields from 3 histological slices for each animal group.

Mucus Layer Determined by Periodic AcidSchiff Staining. The mucus layer was identified by periodic acid-Schiff staining. Briefly, after deparaffinization and rehydration, tissue sections were oxidized in $1 \%$ ( vol/vol) periodic acid for $5 \mathrm{~min}$, then rinsed in distilled water and stained with Schiff's reagent for 10 min. After a second washing with distilled water, tissue sections were counterstained with hematoxylin and rinsed in running tap water. Finally, they were dehydrated, cleared, and mounted. Sections were viewed under a microscope (Leica M LS2) and the thickness of the mucus-secreting layer in corpus and antrum mucosa was assessed under the image analyzer $(1,000 \times)$ and the ratio of mucus gel layer thickness to that of the lamina propria mucosa was calculated as a percentage.

\section{Preparation of Fermented Milks}

Fermented milks were prepared in sterile RSM $10 \%$ (wt/vol; sterilized at $115^{\circ} \mathrm{C}$ for 20 min and cooled down to $37^{\circ} \mathrm{C}$ ) using a $1 \%$ (vol/vol) inoculum of individual active cultures of the $\mathrm{EPS}^{+}$strains Strep. thermophilus CRL 1190 (FM 1190) and CRL 804 (FM 804), and the EPS strain Strep. thermophilus CRL 728 (FM 728), which was used for comparison. Milk cultures were incubated at $37^{\circ} \mathrm{C}$ for $16 \mathrm{~h}$. Nonfermented milk $(\mathbf{M})$ or artificially acidulated milk $(\mathbf{A M})$ to a $\mathrm{pH}=4.5$ 
with D(+)-lactic acid (Sigma Chemical Co.) were used as controls.

\section{Prevention of Chronic Gastritis with FM Using EPS-Producing Strep. thermophilus Strains}

To test for potential antigastritis effect, FM with different Strep. thermophilus strains were evaluated, separately, on the developed chronic gastritis model. Preventively treated mice were divided into 3 groups $(\mathrm{n}=5)$ : group 1 received FM 1190 (FM 1190-ASA); group 2 received FM 804 (FM 804-ASA), and group 3 received FM 728 (FM $\mathbf{7 2 8 - A S A})$. All groups received the FM ad libitum at an approximate dose of $10^{8} \mathrm{cfu} / \mathrm{d}$ for $7 \mathrm{~d}$ (Vinderola et al., 2005; Racedo et al., 2006), followed by ASA administration for $10 \mathrm{~d}$ to induce gastritis. Daily FM consumption was monitored and intake was measured at $5 \mathrm{~mL}$. Mice were killed at $\mathrm{d} 18$ and the gastric inflammatory activity was determined as described above. Two groups $(\mathrm{n}=5$ per group) received M (M-ASA) or AM (AM-ASA) for 7 d, followed by $10 \mathrm{~d}$ of ASA administration; no FM were given to these mice.

To evaluate if any FM per se produced any damaging effect on gastric cells, healthy mice were fed the different FM separately for $7 \mathrm{~d}$ without later gastritis induction; at this time mice were evaluated for gastric inflammatory activity. Control groups (M, AM, and one for each FM) were compared with preventively treated groups (FM-ASA) and the gastritis group.

\section{Evaluation of the EPS Produced by Strep. thermophilus CRL 1190 on Chronic Gastritis}

The EPS produced by Strep. thermophilus CRL 1190 (EPS 1190) was isolated from a $16 \mathrm{~h}$-old culture in RSM $10 \%$ (wt/vol) grown at $37^{\circ} \mathrm{C}$ by using a deproteinization/precipitation technique with $20 \%$ (wt/vol, final concentration) trichloroacetic acid and ethanol (ratio 1:3; Mozzi et al., 2006). The EPS was further purified by dialysis using cellulose membrane sacks (SIGMA Chemical Co.) with a molecular weight cut off of 12,000 against distilled water at $4^{\circ} \mathrm{C}$ for $3 \mathrm{~d}$, with water replacement twice a day (Vaningelgem et al., 2004). The purified EPS was freeze-dried and stored at $4^{\circ} \mathrm{C}$ until use.

The EPS 1190 was dissolved in RSM 10\% (wt/vol; M-EPS 1190) or in water (W-EPS 1190) and administered intragastrically at a dose of $4 \mathrm{mg} / \mathrm{kg}$ of BW per $\mathrm{d}$ for $7 \mathrm{~d}$ followed by ASA administration (M-EPS 1190-ASA and W-EPS 1190-ASA) for $10 \mathrm{~d}$. The amount of EPS administered was calculated based on the EPS received by the mice when they were fed FM 1190. At the end of the treatment (d 18), the stomachs were removed and processed to evaluate the gastric inflammatory activity as described earlier. Mice receiving the EPS but not administered ASA were used as controls to assess the effect of the EPS per se on the gastric mucosa.

\section{Statistical Analysis}

The experimental data were expressed as mean values \pm standard deviations and statistically evaluated by ANOVA with the SPSS software. Multiple group data were analyzed using one-way ANOVA and Tukey multiple comparison test. Differences were considered statistically significant at $P<0.05$.

\section{RESULTS}

\section{Induction of Chronic Gastritis by ASA}

The absence of gastritis was confirmed in healthy mice (group $\mathrm{H}$; controls, receiving drinking water and balanced food only). The gastritis group $(G)$ received oral administration of ASA at doses of $400 \mathrm{mg} / \mathrm{kg}$ per d for $10 \mathrm{~d}$, which successfully induced superficial gastritis with predominance on the gastric corpus rather than on the antral region (Figure 1B). Moderate infiltration with scattered lymphocytes and macrophages in the surface of the mucosa and fold mucosa, into the submucosa direction, without formation of lymphoid follicles was observed, allowing classifying the induced lesions as superficial chronic gastritis with inflammation score $=2$. Regarding the histological structures, no significant increase in the polymorphonuclear infiltration of the normal gastric mucosa was observed. No significant changes in $\mathrm{BW}$ or stomach weight were found during the entire experimental period compared with those of the healthy group (H; Table 2). The number of cytokineproducing cells of the stomachs from the gastritis group (treated with ASA) showed a significant decrease (50\%) in the regulatory cytokine (IL-10 ${ }^{+}$)-producing cells and a similar increase in the pro-inflammatory cytokine $\left(\mathrm{IFN}-\gamma^{+}\right)$-producing cells respect to healthy mice $(\mathrm{H}$; Figure 2). In the gastritis group, the thickness of the mucus gel layer was significantly decreased in both the corpus (80\%) and antrum (85\%) mucosa as compared with the $\mathrm{H}$ group. Acetyl-salicylic acid exposure resulted in a disruption of the protective mucus layer.

\section{Prevention of Chronic Gastritis With FM Using EPS-Producing Strep. thermophilus Strains}

Mice receiving a preventive treatment against gastritis were fed with 3 different FM, separately, for $7 \mathrm{~d}$ before gastritis induction with ASA. Stomachs of mice 
Table 2. Body and stomach weight and gastric $\mathrm{pH}$ of mice belonging to treatment groups

\begin{tabular}{|c|c|c|c|}
\hline $\begin{array}{l}\text { Experimental group } \\
\text { and treatment }^{1}\end{array}$ & $\mathrm{BW}(\mathrm{g})^{2}$ & $\begin{array}{l}\text { Stomach weight } \\
(\mathrm{g} / \mathrm{g} \text { of } \mathrm{BW})\end{array}$ & $\begin{array}{c}\text { Gastric } \\
\mathrm{pH}\end{array}$ \\
\hline \multicolumn{4}{|l|}{ Controls } \\
\hline $\mathrm{H} / \mathrm{M}$ & $28.8 \pm 1.0^{\mathrm{a}}$ & $0.020 \pm 0.007^{\mathrm{a}}$ & 2.0 \\
\hline $\mathrm{AM}$ & $33.0 \pm 2.3^{\mathrm{b}}$ & $0.018 \pm 0.009^{\mathrm{a}}$ & 3.7 \\
\hline FM 728 & $30.7 \pm 0.9^{\mathrm{b}}$ & $0.013 \pm 0.007^{\mathrm{a}}$ & 5.5 \\
\hline FM 804 & $31.0 \pm 0.7^{\mathrm{b}}$ & $0.016 \pm 0.005^{\mathrm{a}}$ & 4.6 \\
\hline FM 1190 & $30.9 \pm 1.2^{\mathrm{b}}$ & $0.019 \pm 0.001^{\mathrm{a}}$ & 5.7 \\
\hline M-EPS 1190 & $32.5 \pm 1.7^{\mathrm{b}}$ & $0.019 \pm 0.002^{\mathrm{a}}$ & 3.8 \\
\hline W-EPS 1190 & $35.4 \pm 1.4^{\mathrm{b}}$ & $0.013 \pm 0.001^{\mathrm{a}}$ & 3.8 \\
\hline \multicolumn{4}{|l|}{ Gastritis (G) } \\
\hline G/M-ASA & $31.3 \pm 0.8^{\mathrm{b}}$ & $0.016 \pm 0.005^{\mathrm{a}}$ & 3.5 \\
\hline AM-ASA & $37.6 \pm 3.4^{\mathrm{b}}$ & $0.032 \pm 0.003^{\mathrm{b}}$ & 3.6 \\
\hline FM 728-ASA & $30.2 \pm 0.5^{\mathrm{b}}$ & $0.040 \pm 0.0003^{\mathrm{b}}$ & 5.7 \\
\hline FM 804-ASA & $30.5 \pm 0.9^{\mathrm{b}}$ & $0.020 \pm 0.006^{\mathrm{a}}$ & 4.8 \\
\hline FM 1190-ASA & $30.5 \pm 0.8^{\mathrm{b}}$ & $0.015 \pm 0.001^{\mathrm{a}}$ & 5.9 \\
\hline M-EPS 1190-ASA & $29.5 \pm 2.7^{\mathrm{b}}$ & $0.013 \pm 0.001^{\mathrm{a}}$ & 4.0 \\
\hline W-EPS 1190-ASA & $29.5 \pm 3.6^{\mathrm{b}}$ & $0.015 \pm 0.001^{\mathrm{a}}$ & 4.0 \\
\hline
\end{tabular}

${ }^{\mathrm{a}, \mathrm{b}}$ Different letters indicate a significant difference $(P<0.05)$ within columns.

${ }^{1} \mathrm{H}=$ healthy control; $\mathrm{M}=$ nonfermented milk; $\mathrm{AM}=$ artificially acidulated milk; $\mathrm{G}=$ gastritis group; $\mathrm{FM}$ $728=$ fermented milk with Strep. thermophilus CRL 728; FM $804=$ fermented milk with Strep. thermophilus CRL 804; FM 1190 = fermented milk with Strep. thermophilus CRL 1190; M-EPS $1190=$ exopolysaccharide produced by Strep. thermophilus CRL 1190 resuspended in milk; W-EPS $1190=$ exopolysaccharide produced by Strep. thermophilus CRL 1190 resuspended in water; -ASA indicates groups receiving acetyl-salicylic acid. ${ }^{2}$ No significant differences were observed in the BW before and after each treatment. Data are reported as mean value \pm standard deviation.

from groups M-ASA and AM-ASA as well as those preventively fed with FM 728-ASA $\left(\mathrm{EPS}^{-}\right)$and FM 804-ASA $\left(\mathrm{EPS}^{+}\right)$showed mononuclear inflammatory infiltrations (scores: 2-3, moderate to severe, Figure 3 ) in their histological structures similar to those of the gastritis group $(\mathrm{G})$ at d 18 (sacrifice day; Figure
4). Interestingly, only stomachs from FM 1190-ASA group displayed no leukocyte infiltration on the gastric mucosa at the same period (Figure 4C). Milk alone or FM without later gastritis induction did not cause any damage per se on the mice's gastric mucosa, whereas the AM had a similar negative effect to ASA. In addi-

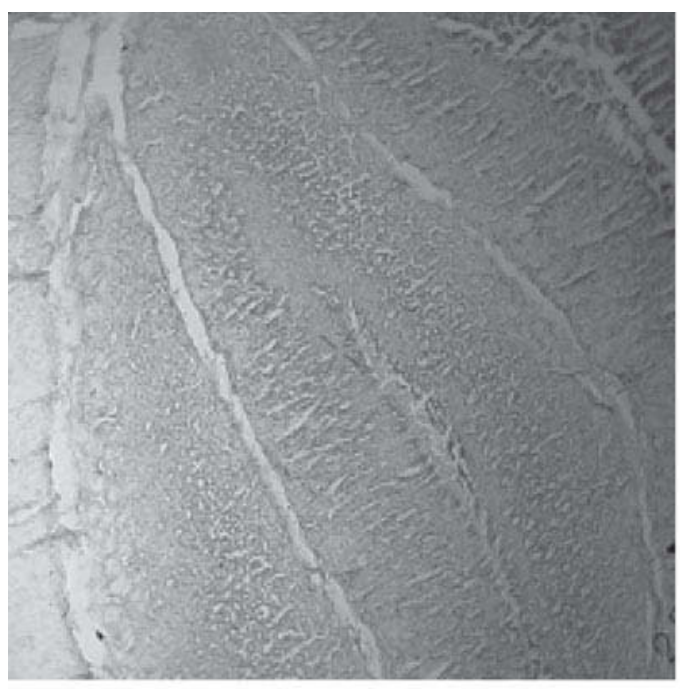

(A)

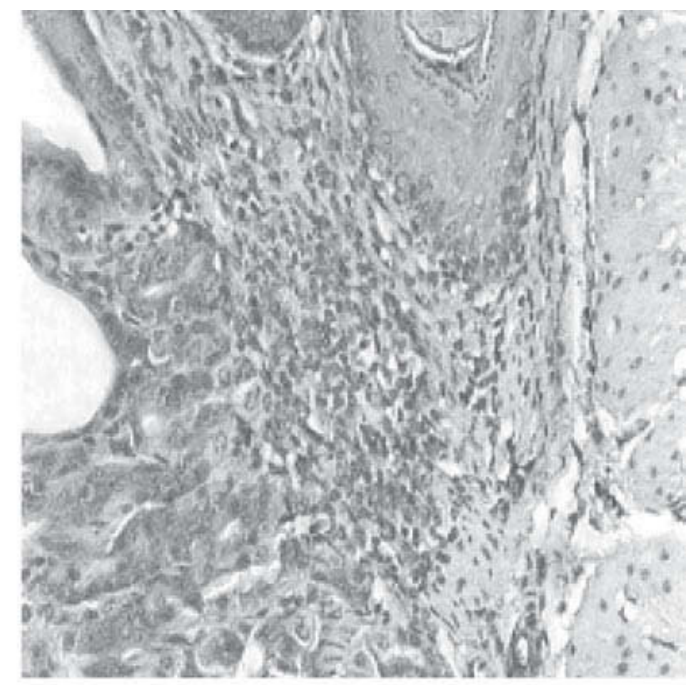

(B)

Figure 1. Light micrographs (original magnification 1,000×) of hematoxylin-eosin stained mouse gastric mucosa belonging to different experimental groups: A) healthy group $(\mathrm{H})$; and $\mathrm{B}$ ) gastritis group $(\mathrm{G})$, which shows lymphocytes and macrophage infiltration in the superficial mucosa. 
H (Healthy control) group

G (Gastritis) group

M (Milk) group

$\triangle \mathrm{AM}$ (Artificially acidulated milk) group

FM 728 (fermented milk with Strep. thermophilus CRL 728) group

FM 804 (Fermented milk with Strep. thermophilus CRL 804) group

区 FM 1190 (Fermented milk with Strep. thermophilus CRL 1190) group

$\bigotimes$ M-EPS 1190 (EPS produced by Strep. thermophilus CRL 1190 dissolved in milk) group

W-EPS 1190 (EPS produced by Strep. thermophilus CRL 1190 dissolved in water) group

A
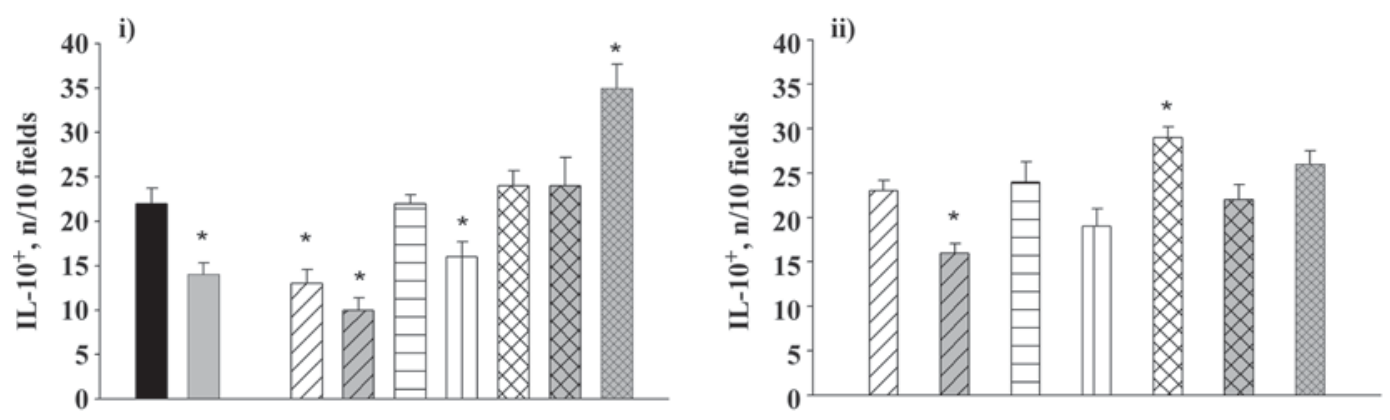

B
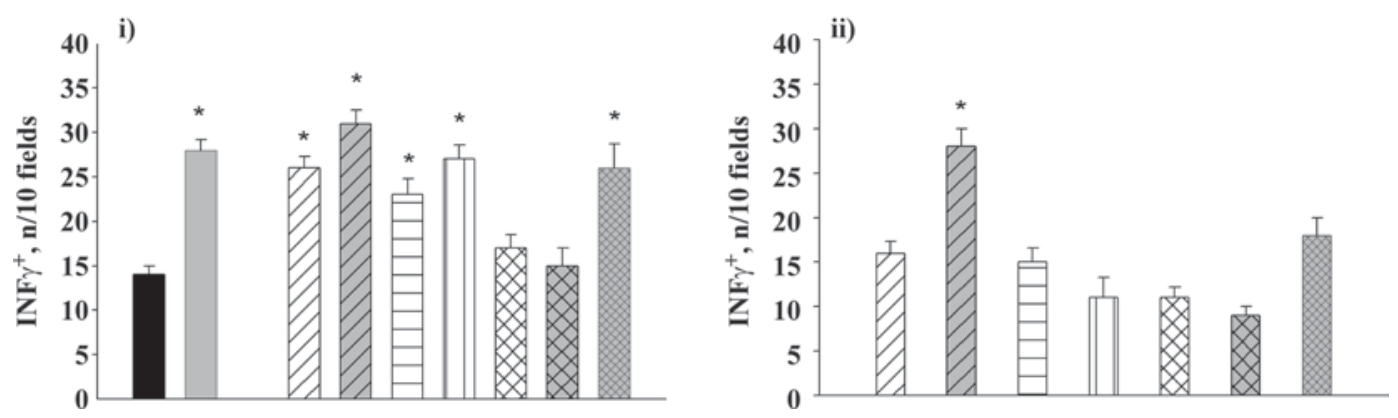

Figure 2. Effect of preventive treatments with different fermented milks or exopolysaccharide suspension from Streptococcus thermophilus CRL 1190 and oral administration of acetyl-salicylic acid on the number of A) IL- $10^{+}-$and B) IFN- $\gamma^{+}$-producing cells on histological slices of mice stomachs; i) preventive treatments on gastritis, and ii) control groups without gastritis induction. Results are presented as means of 3 determinations and are expressed as the number of IFN- $\gamma$ and IL-10-producing cells per 10 fields (original magnification $100 \times$ ). $* P<0.05$ compared with the controls.

tion, the AM alone caused translucent and thin gastric walls as well as dark fecal matter, probably due to the presence of blood (Figure 4).

In general, no significant changes in BW or stomach weight values were found during the experimental period for mice from any group with exception of those from the AM-ASA and FM 728-ASA groups (Table 2 ), which showed the highest stomach weight values at the end of the experimental period (d 18). No correla- tion between stomach weight and induced gastritis was found.

The mice preventively treated with M, AM, and FM 804 showed a significant decrease in the number of IL- $10^{+}$-cells and an increase in the number of IFN $\gamma^{+}$producing cells similar to those of the G group (Figure 2 ). Mice treated with FM 728-ASA (EPS-) showed only an increase in IFN $\gamma^{+}$-producing cells (Figure 2B). Best results were obtained with FM 1190-ASA, which 


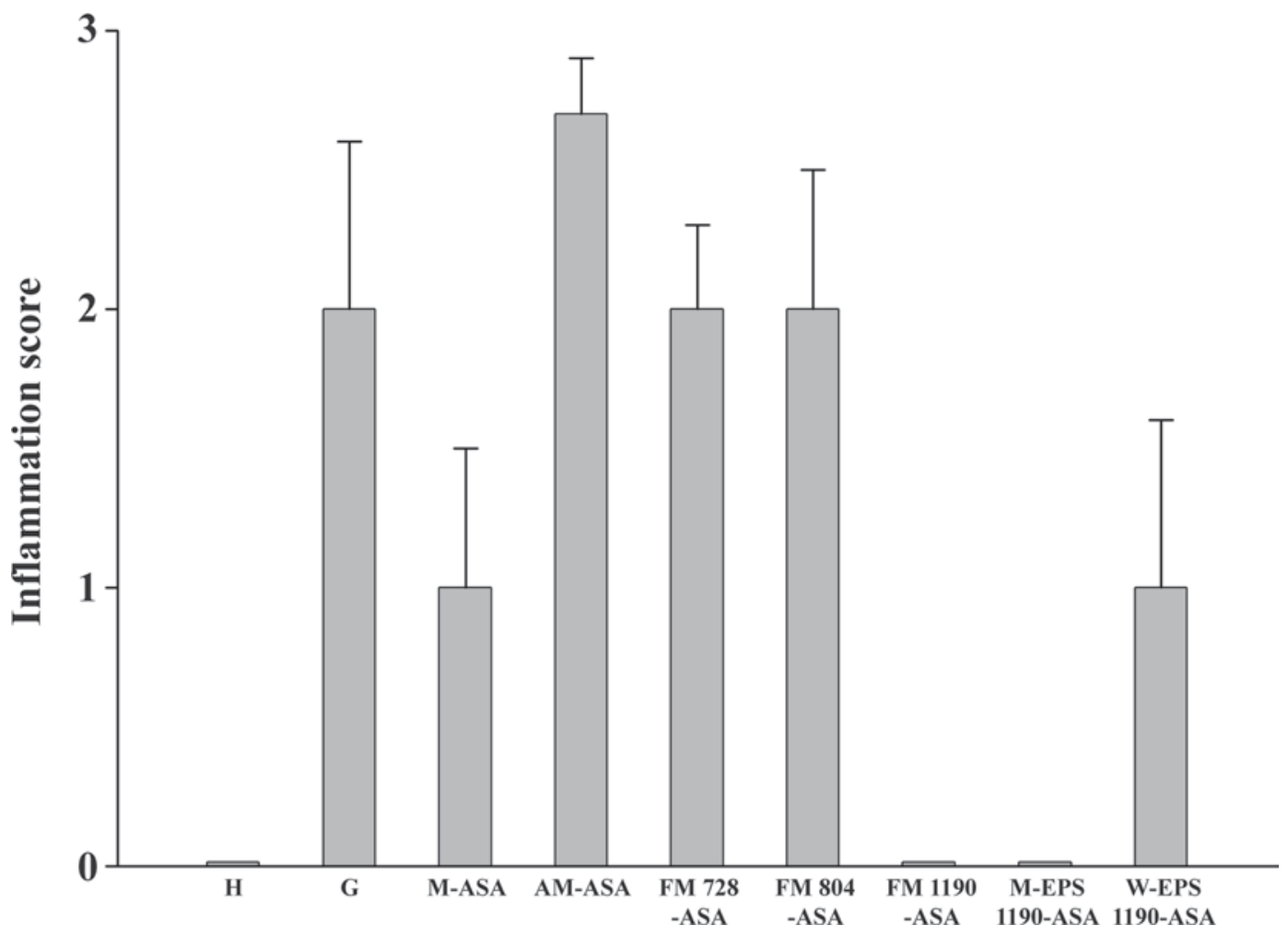

Figure 3. Histopathological inflammation score of healthy control group $(\mathrm{H})$; gastritis group $(\mathrm{G})$; and mice preventively treated for gastritis induced by acetyl-salicylic acid: milk group (M-ASA); artificially acidulated milk group (AM-ASA); fermented milk with Streptococcus thermophilus CRL 728 group (FM 728-ASA); fermented milk with Strep. thermophilus CRL 804 group (FM 804-ASA); fermented milk with Strep. thermophilus CRL 1190 group (FM 1190-ASA); exopolysaccharide produced by Strep. thermophilus CRL 1190 dissolved in milk group (M-EPS 1190-ASA); exopolysaccharide produced by Strep. thermophilus CRL 1190 dissolved in water group (W-EPS 1190-ASA). Data are expressed as means \pm SD.

produced a decrease $(17 \pm 1.5$ cells $/ 10$ fields $)$ in the number of IFN $\gamma^{+}$-producing cells and an increase $(24$ \pm 1.7 cells $/ 10$ fields) in the $\mathrm{IL}-10^{+}$-producing cells comparing to the $\mathrm{H}$ group, regulating the gastric inflammatory process. The administration of FM without gastritis induction (FM 728, FM 804, and FM 1190 groups) showed no significant differences in the assayed cytokines respect to the values of healthy mice $(\mathrm{H})$ or those that received milk only (M; Figure 2). Only mice belonging to the FM 1190 group displayed a significant increase in the IL- $10^{+}$-producing cells. The AM group showed cytokines values similar to those of the G group (Figure 2). In general, a correlation between the histopathological structure and the number of both types of cytokines producing-cells was observed.

The effects of preventive treatment with different FM on mucus secretion in mouse gastric mucosa were studied. The thickness ratio in corpus and antrum mucosa and representative photomicrographs of periodic acidSchiff-stained corpus mucosa from control $(\mathrm{H})$, gastritis $(\mathrm{G})$ and the different preventive treatment groups (FM 1190-ASA, FM 804-ASA, and FM 728-ASA) are shown in Figures 5A and 5B. Histological observation revealed that an important decrease of 80 to $88 \%$ in the mucus gel layer in both corpus and antrum mucosa of mice belonging to all groups, with exception of FM 1190-ASA, compared with the healthy mice was observed. Mice from the FM 1190-ASA group displayed a diminution in the mucus layer (49\% in corpus and $38 \%$ in antrum mucosa) respect to the $\mathrm{H}$ group but an increase the mucus layer between 31 and $47 \%$ (corpus and antrum mucosa, respectively) compared with the G group. These findings showed that FM 1190 administered preventively counteract an important depletion of the gastric mucus by ASA and strengthened the stomach mucosal barrier.

\section{Effect of the EPS Produced by Strep. thermophilus CRL 1190 on Chronic Gastritis}

To evaluate whether the positive effect found with FM 1190 on the chronic gastritis was caused by the EPS produced by Strep. thermophilus CRL 1190, a suspension of the purified EPS 1190 was dissolved in milk or in water and assayed for their potential gastroprotective effect. Only the EPS dissolved in milk 


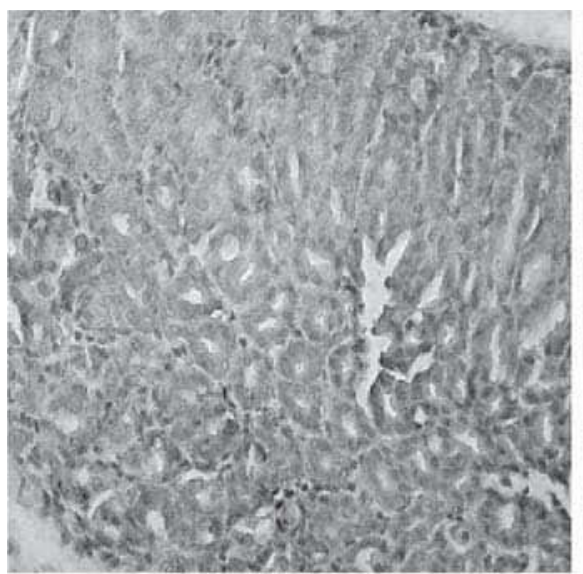

A

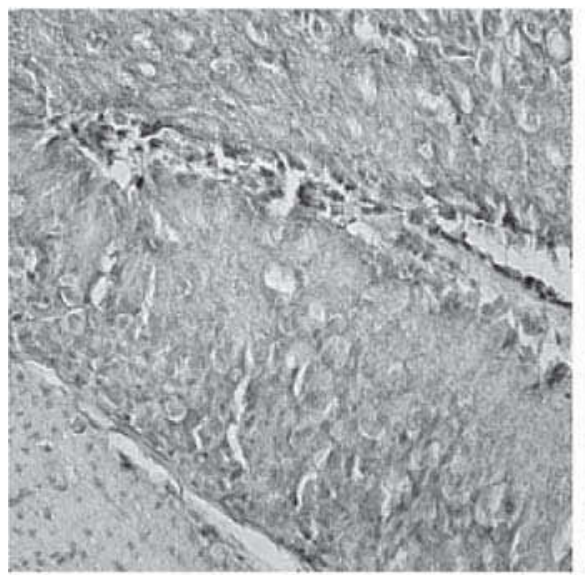

C

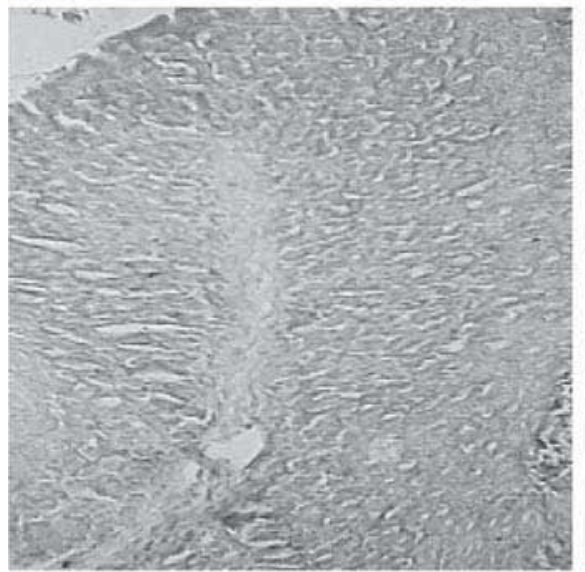

F

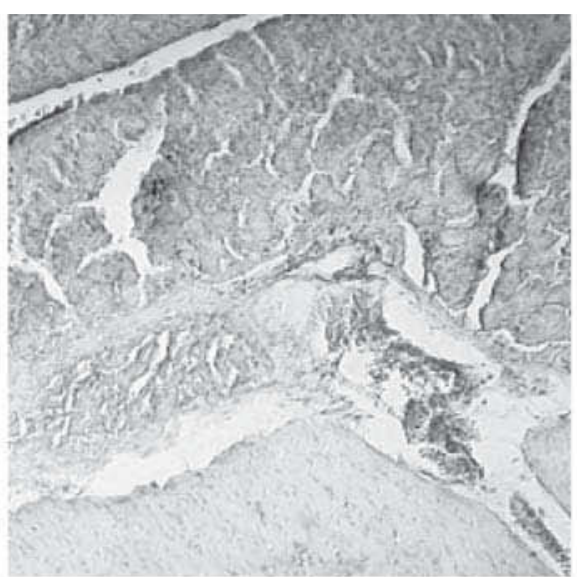

B

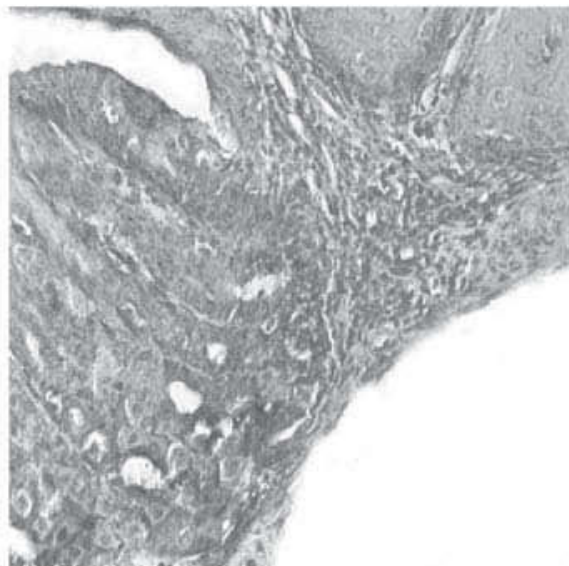

D

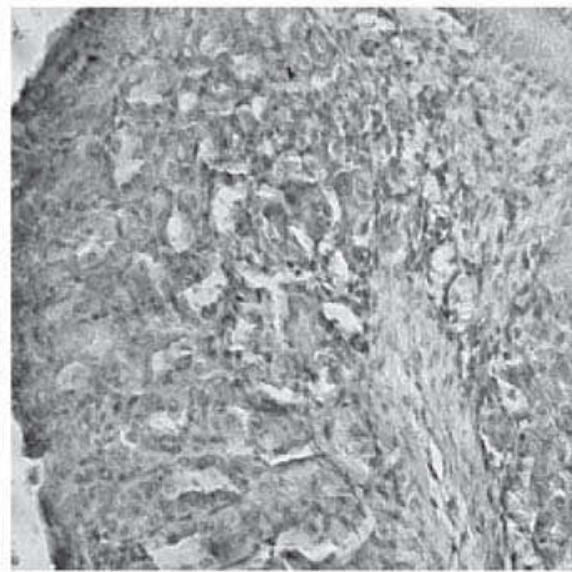

G

Figure 4. Light micrographs (original magnification $100 \times$ ) of hematoxylin-eosin stained gastric mucosa of mice preventively treated on gastritis induced by acetyl-salicylic acid (ASA). Determinations were done at d 18. A) milk group (M-ASA), B) artificially acidulated milk group (AM-ASA), C) fermented milk with Streptococcus thermophilus CRL 728 group (FM 728-ASA), D) fermented milk with Strep. thermophilus CRL 804 group (FM 804-ASA), presenting chronic inflammatory infiltration in mucosa's surface, E) fermented milk with Strep. thermophilus CRL 1190 group (FM 1190-ASA), F) exopolysaccharide produced by Strep. thermophilus CRL 1190 dissolved in milk group (M-EPS 1190-ASA) showed conserved histological structure similar to the control (H), and G) exopolysaccharide produced by Strep. thermophilus CRL 1190 dissolved in water group (W-EPS 1190-ASA) displayed chronic inflammatory infiltration. 


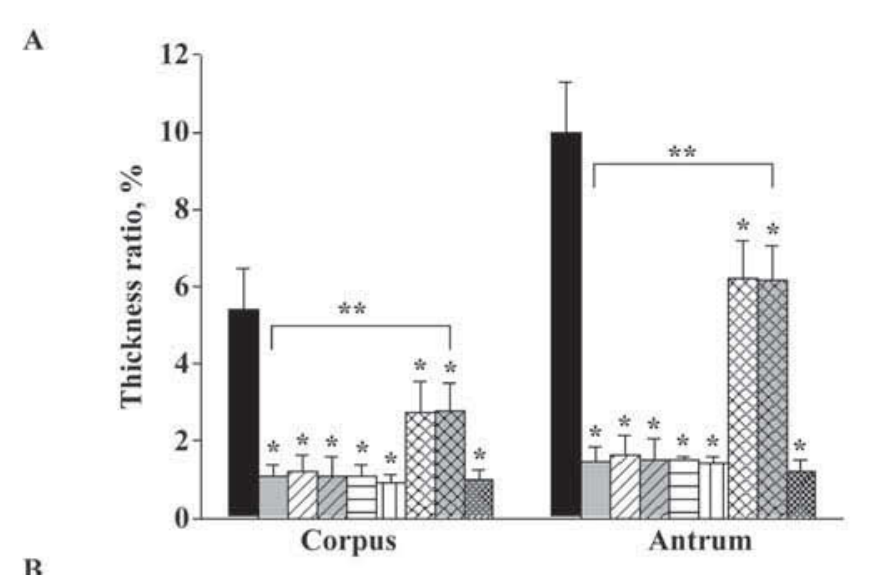

H (Healthy control) group

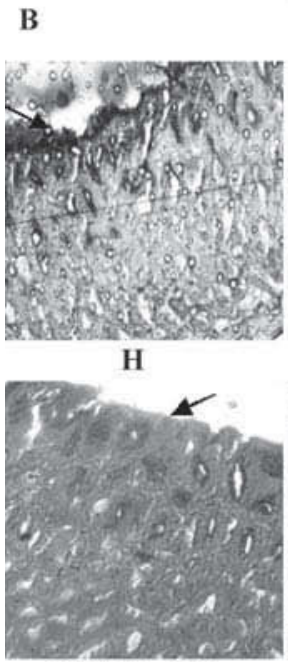

Corpus

$\square$ G (Gastritis) group

$\square$ M (Milk) group

$\square$ AM (Artificially acidulated milk) group

目 FM 728 (fermented milk with Strep. thermophilus CRL 728) group

III FM 804 (Fermented milk with Strep. thermophilus CRL 804) group

$\bigotimes$ FM 1190 (Fermented milk with Strep. thermophilus CRL 1190) group

Q M-EPS 1190 (EPS produced by Strep, thermophilus CRL 1190 dissolved in milk) group

W-EPS 1190 (EPS produced by Strep, thermophilus CRL 1190 dissolved in water) group

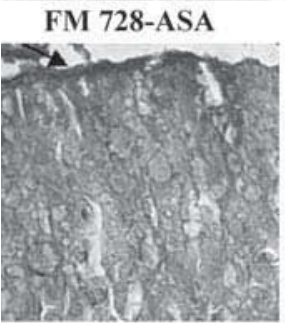

M-EPS 1190-ASA

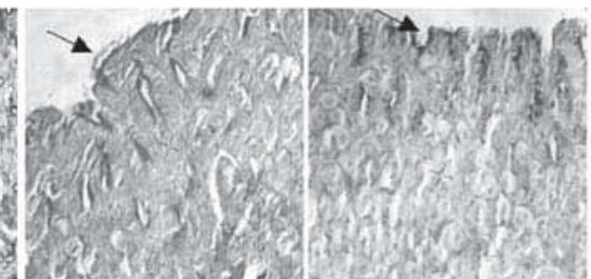

G

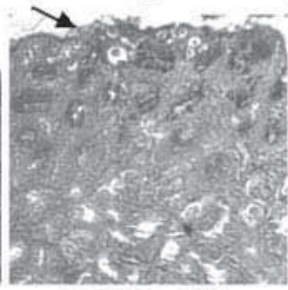

FM 804-ASA

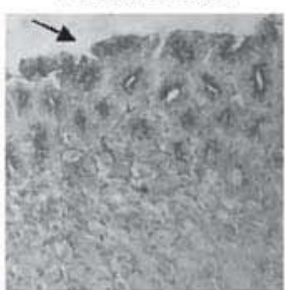

W-EPS 1190-ASA

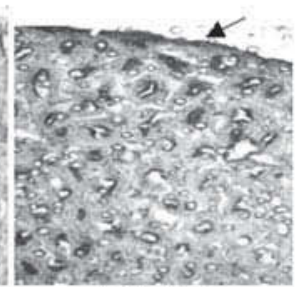

AM-ASA

Figure 5. Effect of preventive treatments with different fermented milks, EPS 1190 and oral administration of acetyl-salicylic acid (ASA) on periodic acid-Schiff-positive mucus on the mice gastric mucosa. Original magnification $=400 \times$. A) Thickness ratio of the mucus gel layer to the lamina propria mucosae in corpus and antrum mucosa. Values represent means \pm SEM for 5 mice. ${ }^{*} P<0.05$ compared with the healthy group $(\mathrm{H}) .{ }^{* *} P<0.05$ compared with the gastritis group $(\mathrm{G})$. B) Representative photomicrographs of corpus mucosa from H, G, M-ASA, AMASA, FM 728-ASA, FM 804-ASA, FM 1190-ASA, M-EPS 1190-ASA, and W-EPS 1190-ASA. Sections were stained using periodic acid-Schiff reagent.

(M-EPS 1190-ASA) successfully prevented gastritis in a similar way to FM 1190. Similar histological and histochemical findings, and number of IFN $\gamma^{+}$and IL$10^{+}$-producing cells to those of healthy mice $(\mathrm{H})$ were found. No significant changes in BW or stomach weight were observed during the entire experimental period.

\section{DISCUSSION}

A murine model of chronic gastritis using ASA as gastric inductor was successfully standardized in this work. Different gastritis and gastric ulcer inductors such as chloridric or acetic acid, ethanol, indomethacin, and iodoacetamide have been previously used in animal models, usually causing acute lesions (Gomes et al., 2006; Lam et al., 2007). The gastritis model developed here could be applied to evaluate gastritis in humans, as it is well known that ASA is one of the main causes of gastric damage in people having an excessive consumption of this antiinflammatory drug (Fries et al., 1991; Aalykke and Lauritsen, 2001). 
Nagaoka et al. (1994) reported on Bifidobacterium and Streptococcus strains that were effective in healing ulcers induced by acetic acid; this effect was also observed with the cell wall polysaccharides, particularly those with rhamnose content higher than $60 \%$ (Nagaoka et al., 1994). Our work shows for the first time the preventive effect of FM with EPS-producing strains on gastric mucosa chronic lesions induced by ASA as a safer and natural gastroprotective alternative. Two EPS-producing strains (Strep. thermophilus CRL 1190 and CRL 804) and a non-EPS-producing one (Strep. thermophilus CRL 728) were employed. Streptococcus thermophilus CRL 1190 produced a high MM $\left(1,782 \mathrm{kDa}\right.$; arbitrarily defined as $\left.>1 \times 10^{6} \mathrm{Da}\right) \mathrm{HePS}$ composed of D-glucose and D-galactose while Strep. thermophilus CRL 804 produced a low MM (95 kDa) HePS composed of D-galactose and L-rhamnose (Mozzi et al., 2006). The former strain produced CPS in addition to the slime EPS in milk and was able to form ropy milk cultures while Strep. thermophilus CRL 804 was negative for both the CPS and ropy phenotypes. Only the treatment with FM 1190-ASA showed significant $(P<0.05)$ gastroprotector and immunomodulator effects (Figure 2) and tended to normalize the values of the proinflammatory cytokine $\left(\mathrm{IFN}-\gamma^{+}\right)$, probably due to the inhibition of IL-10 on T-helper 1 (Kidd, 2003). Macrophages and lymphocytes play an important role in the cell-mediated and humoral immune responses through the release of proinflammatory cytokines, such as IFN- $\gamma$, associated with immune activation and tissue injury, and the regulatory cytokines like IL-10, known to inhibit the synthesis of IFN- $\gamma$ (Kidd, 2003; Vinderola et al., 2004). Yamamoto et al. (2004) showed that IFN- $\gamma$ plays a role in the induction of gastric inflammation caused by H. pylori. Recently, Vinderola et al. (2005) reported that the administration of pasteurized kefir, a milk fermented by lactic and acetic acid bacteria and yeasts, produced a significant increase in the proinflammatory cytokines (IFN- $\gamma$ and TNF- $\alpha$ ) on the intestinal mucosal immune response in mice, but the magnitude of this increment was lower than the one for the cytokine IL-10. Neutrophil infiltration in gastric tissue was also quantified by measuring myeloperoxidase activity (data not shown); this enzyme is primarily found in azurophilic granules of neutrophils and is used extensively as a biochemical marker of granulocyte infiltration into various tissues, including the gastrointestinal tract (Gomes et al., 2006). In our work, myeloperoxidase activity could not be used as a marker in the chronic gastritis model as the values obtained in the gastric tissue of mice from both groups (gastritis and healthy) were similar.

Because of the positive effect on gastritis prevention by FM 1190 but not by milk itself, the EPS produced by Strep. thermophilus CRL 1190 was isolated, purified, and evaluated for its potential gastroprotector effect. The EPS was dissolved in milk or water to evaluate whether EPS-milk protein interaction could have a positive effect. The EPS suspended in milk (M-EPS 1190-ASA) showed a gastroprotector effect and was able to modulate the inflammatory response in a similar way to FM 1190-ASA, while that of the polysaccharide suspension in water (W-EPS 1190-ASA) showed no positive effect on the inflamed gastric mucosa. These findings suggest that some of EPS-milk protein interactions are responsible for the observed gastroprotective effect. Associative interactions between proteins and polysaccharides are of relevance for many products in both food and pharmaceutical science (Tolstoguzov, 2002). Certain manufacturing parameters such as temperature, pressure, etc., may influence the formation and the stability of such complexes (Weinbreck et al., 2003). Possible protein denaturation/aggregation and Maillard reaction of sugars may occur (Peyron et al., 2006); modifications in such interactions might lead to a different gastroprotective effect. Certain whey proteins have been reported to possess biological functions including immunomodulatory activities. Matsumoto et al. (2001) studied the gastroprotective activities of bovine whey proteins in experimental gastric ulcer models and showed that the orally administered whey protein fraction exhibited preventive effects against ethanolinduced ulcers in rats, and that $\alpha$-lactalbumin played a central role in this activity, stimulating mucin synthesis and secretion in mucus-producing cells (Uchida et al., 2007).

The EPS 1190 did not contain rhamnose in its monomer composition, contrary to the ulcer-healing polysaccharides reported by Nagaoka et al. (1994). In contrast, the EPS produced by Strep. thermophilus CRL 804 contained rhamnose in addition to glucose and had no positive effect on the gastritis induced by ASA in this work. The different effects observed for FM 1190 and FM 804 on gastritis could be ascribed to the greater polymer size (MM) of EPS 1190 compared with that of EPS 804, independent of their monomeric composition. Yamada (1995) found that a bioactive peptic polysaccharide isolated from Chinese herbs was a potent antiulcer compound in experimental $\mathrm{HCl}-$ ethanol induced ulcers. The author suggested that the mucosal protection might be related to an antisecretory activity on acid and pepsin by the high MM pectin polysaccharide. In addition, Sengül et al. (2005) showed that a high MM EPS produced by the probiotic strain Lactobacillus delbrueckii ssp. bulgaricus B3 significantly attenuated experimental colitis in rats.

On the other side, it has been claimed that milk is beneficial for the healing of gastric mucosal lesions, 
probably because of membrane stabilization and gastric cellular restitution by the calcium present in milk (Koo, 1994). However, Ippoliti et al. (1976) reported that milk contains both proteins and calcium that stimulate gastric acid secretion. In the present study, the number of cytokine-producing cells in the nonfermented milk (M) used as control showed no gastroprotective effect per se. Similar results were obtained by Ushida and Kurakazu (2004), who showed that nonfermented milks did not inhibit, but slightly aggravated, the $\mathrm{HCl}$-induced acute gastric lesions using doses of $5 \mathrm{~mL} / \mathrm{kg}$ in rats. Moreover, we observed that the artificially acidulated milk (AM) had no positive effect on the chronic gastritis, suggesting that the gastric modulation of the inflammatory response was caused by FM with the EPS-producing strain Strep. thermophilus CRL 1190 or its EPS.

The mucosal surface of the stomach is covered by thick layers of mucus composed of mucin, water, proteoglycans, electrolytes, DNA, and serum proteins, which act as a physical barrier to prevent cell damage caused by the gastric juice and exogenous irritants (Allen et al., 1986). We evaluated the mucus gel layer thickness in mouse gastric mucosa using histochemical methods. Acetyl-salicylic acid exposure significantly reduced the thickness of the mucus layer in both corpus and antrum mucosa ( 80 and $85 \%$, respectively) with respect to the healthy group. When mice received different treatments for the induced gastritis, only FM 1190-ASA and MEPS 1190-ASA counteracted the mucus reduction in both gastric regions compared with the $\mathrm{G}$ group. This finding suggests that S. thermophilus CRL 1190 and its EPS fortifies the mucus gel layer in gastric mucosa. Lam et al. (2007) demonstrated similar effects on the mucus layer caused by ethanol exposure using Lactobacillus rhamnosus $\mathrm{GG}$.

In the dairy industry, pasteurized milk is employed for producing fermented dairy products. In this work, autoclaved rather than pasteurized milk was used for preparing FM or isolating EPS from the assayed LAB strains. As culture medium may affect the structure or MM of the EPS produced (Looijesteijn et al., 2000, Petry et al., 2003, Vaningelgem et al., 2004), further studies are required for industrial exploitation of FM made with the EPS-producing $S$. thermophilus CRL 1190 or its EPS to evaluate whether their gastroprotector effect is maintained under industrial manufacturing conditions.

\section{CONCLUSIONS}

The results obtained in this work suggest that the gastroprotective effect displayed by FM with Strep. thermophilus CRL 1190 or its EPS was efficient in prevention of the chronic gastritis model developed here.
These treatments were also able to modulate mice immune response.

\section{ACKNOWLEDGMENTS}

We thank Consejo Nacional de Investigaciones Científicas y Técnicas (CONICET), Agencia Nacional de Promoción Científica y Tecnológica (ANPCyT; project BID 1728 OC/AR PICTR 20801) and Consejo de Investigaciones de la Universidad Nacional de Tucumán (CIUNT) of Argentina for financial support. C. Rodríguez is recipient of a doctoral fellowship from CONICET, Argentina.

\section{REFERENCES}

Aalykke, C., and K. Lauritsen. 2001. Epidemiology of NSAIDrelated gastroduodenal mucosal injury. Best. Pract. Res. Clin. Gastroenterol. 15:705-722.

Allen, A., D. A. Hutton, A. J. Leonard, J. P. Pearson, and L. A. Sellers, 1986. The role of mucus in the protection of the gastroduodenal mucosa. Scand. J. Gastroenterol. Suppl. 125:71-78.

Ashley, S. W., L. A. Sonnenschein, and L. Y. Cheung. 1985. Focal gastritis mucosal blood flow at the site of aspirin-induced ulceration. Am. J. Surg. 149:53-59.

Burns, A. J., and I. R. Rowland. 2000. Anti-carcinogenicity of probiotics and prebiotics. Curr. Issues Intest. Microbiol. 1:13-24.

Canadian Council on Animal Care. 1998. Guide to the Care and Use of Experimental Animals. Vol. 1. 2nd ed. E. D. Olfert, B. M. Cross, A. A. Mc William, ed. CCAC, Ottawa, Ontario, Canada

Collado, M. C., M. Gueimonde, M. Hernández, Y. Sanz, and S. Salminen. 2005. Adhesion of selected Bifidobacterium strains to human intestinal mucus and the role of adhesion in enteropathogen exclusion. J. Food Prot. 68:2672-2678.

De Vuyst, L., and B. Degeest. 1999. Heteropolysaccharides from lactic acid bacteria. FEMS Microbiol. Rev. 23:153-177.

Dixon, M. F., R. M. Genta, J. H. Yardley, and P. Correa. 1996. Classification and grading of gastritis. The updated Sydney system. Am. J. Surg. Pathol. 20:1161-1181.

Drago, L., M. R. Gismondo, A. Lombardi, C. de Haen, and L. Gozzini. 1997. Inhibition of in vitro growth of enteropathogens by new Lactobacillus isolates of human intestinal origin. FEMS Microbiol. Lett. 153:455-463.

FAO/WHO. 2001. Report on joint FAO/WHO expert consultation on evaluation of health and nutritional properties of probiotics in food including powder milk with live lactic acid bacteria. ftp://ftp.fao. org/docrep/fao/meeting/009/y6398e.pdf

Fries, J. F., C. A. Williams, and D. A. Bloch. 1991. The relative toxicity of nonsteroidal anti-inflammatory drugs. Arthritis Rheum. 34:1353-1360.

Gomes, A. S., L. M. Lima, C. L. Santos, F. Q. Cunha, R. A. Ribeiro, and M. H. Souza. 2006. LPS from Escherichia coli protects against indomethacin-induced gastropathy in rats role of ATP-sensitive potassium channels. Eur. J. Pharmacol. 547:136-142.

Ippoliti, A. F., V. Maxwel, and J. I. Isemberg. 1976. The effect of various forms of milk on gastric-acid secretion. Ann. Intern. Med. $84: 286-289$.

Johnson-Henry, K. C., D. J. Mitchell, Y. Avitzur, E. Galindo-Mata, N. L. Jones, and P. M. Sherman. 2004. Probiotics reduce bacterial colonization and gastric inflammation in $H$. pylori-infected mice. Dig. Dis. Sci. 49:1095-1102.

Kalliomäki, M., S. Salminen, and E. Isolauri. 2008. Positive interactions with the microbiota: Probiotics. Adv. Exp. Med. Biol. 635:5766.

Kidd, P. 2003. Th1/Th2 balance: The hyphotesis, its limitations, and implications for health and disease. Altern. Med. Rev. 8:223246. 
Kitazawa, H., T. Toba, T. Itoh, N. Kumano, S. Adachi, and T. Yamaguchi. 1991. Antitumoral activity of slime-forming encapsulated Lactococcus lactis subsp. cremoris isolated from Scandinavian ropy sour milk, "viili." Anim. Sci. Technol. 62:277283.

Koo, M. W. L. 1994. The effects of milk and calcium on ethanolinduced gastric mucosal damage. Pharmacol. Res. 29:217-224.

Lam, E. K. Y., E. K. K. Tai, M. W. L. Koo, H. P. S. Wong, W. K. K. Wu, L. Yu, W. H. L. So, P. C. Y. Woo, and C. H. Cho. 2007. Enhancement of gastric mucosal integrity by Lactobacillus rhamnosus GG. Life Sci. 80:2128-2136.

Lamarque, D. 2004. Pathogenesis of gastroduodenal lesions induced by non-steroidal anti-inflammatory drugs. Gastroenterol. Clin. Biol. 3:18-26.

Looijesteijn, P. J., W. H. M. van Casteren, R. Tuinier, C. H. L. Doeswijk-Voragen, and J. Hugenholtz. 2000. Influence of different substrate limitations on the yield, composition and molecular mass of exopolysaccharides produced by Lactococcus lactis subsp. cremoris in continuous cultures. J. Appl. Microbiol. 89:116-122.

Matsumoto, H., Y. Shimokawa, Y. Ushida, T. Toida, and H. Hayasawa. 2001. New biological function of bovine $\alpha$-lactalbumin: Protective effect against ethanol- and stress-induced gastric mucosal injury in rats. Biosci. Biotechnol. Biochem. 65:1104-1111.

Mozzi, F., F. Vaningelgem, E. M. Hébert, R. Van der Meulen, M. R. Foulquié Moreno, G. Font de Valdez, and L. De Vuyst. 2006. Diversity of heteropolysaccharide-producing lactic acid bacterium strains and their biopolymers. Appl. Environ. Microbiol. 72:44314435.

Nagaoka, M., S. Hashimoto, T. Watanabe, T. Yokokura, and Y. Moro, 1994. Anti-ulcer effects of lactic acid bacteria and their cell wall polysaccharides. Biol. Pharm. Bull. 17:1012-1017.

Nakajima, H., H. Suzuki, H. Kaizu, and T. Hirota. 1992. Cholesterol lowering activity of ropy fermented milk. J. Food Sci. 57:13271329.

Perdigón, G., C. Maldonado-Galdeano, A. de Moreno de LeBlanc, C. G. Vinderola, M. Medici, and M. E. Bibas Bonet. 2004 Immunomodulation of mucosal immune response by probiotics. Curr. Trends Immunol. 6:69-85.

Petry, S., S. Furlan, E. Waghorne, L. Saulnier, J. Cerning, and E. Maguin. 2003. Comparison of thickening properties of four Lactobacillus delbrueckii subsp. bulgaricus strains and physicochemical characterization of their exopolysaccharides. FEMS Microbiol. Lett. 221:285-291.

Peyron, S., J. Mouécoucou, S. Frémont, C. Sánchez, and N. Gontard. 2006. Effects of heat treatment and pectin addition on $\beta$-lactoglobulin allergenicity. J. Agric. Food Chem. 54:56435650.

Plummer, S., M. A. Weaver, J. C. Harris, P. Dee, and J. Hunter. 2004. Clostridium difficile pilot study: Effects of probiotic supplementationon the incidence of $C$. difficile diarrhea. Int. Microbiol. 7:59-62.

Racedo, S., J. Villena, M. Medina, G. Agüero, V. Rodríguez, and S. Alvarez. 2006. Lactobacillus casei administration reduces lung injuries in a Streptococcus neumoniae infection in mice. Microbes Infect. 8:2359-2366.

Roberts, I. S. 1996. The biochemistry and genetics of capsular polysaccharides production in bacteria. Annu. Rev. Microbiol. 50:285-315.

Ruas-Madiedo, P., and C. G. De los Reyes-Gavilán. 2005. Invited review: Methods for the screening, isolation and characterization of exopolysaccharides produced by lactic acid bacteria. J. Dairy Sci. 88:843-856.

Ruas-Madiedo, P., J. Hugenholtz, and P. Zoon. 2002. An overview of the functionality of exopolysaccharides produced by lactic acid bacteria. Int. Dairy J. 12:163-171.

Saint-Marie, G. 1962. A paraffin embedding technique for studies employing immunofluorescence. J. Histochem. Cytochem. 10:250256.

Sanders, M. E. 1998. Overview on functional foods: Emphasis on probiotic bacteria. Int. Dairy J. 8:341-347.

Sengül, M., B. Aslím, G. Ucar, N. Yücel, S. Isik, H. Bozkurt, Z Sakaogullari, and F. Atalay. 2005. Effects of exopolysaccharideproducing probiotic strains on experimental colitis in rats. Dis. Colon Rectum 49:250-258.

Sgouras, D., P. Maragkoudakis, K. Petraki, B. Martinez-Gonzalez, E. Eriotou, S. Michopoulos, G. Kalantzopoulos, E. Tsakalidou, and A. Mentis. 2004. In vitro and in vivo inhibition of Helicobacter pylori by Lactobacillus casei strain Shirota. Appl. Environ. Microbiol. 70:518-526.

Stanton, C. R. P. Ross, G. F. Fitzgerald, and D. Van Sinderen. 2005 Fermented functional foods based on probiotics and their biogenic metabolites. Curr. Opin. Microbiol. 16:198-203.

Tolstoguzov, V. B. 2002. Thermodynamic aspects of biopolymers functionality in biological systems, foods, and beverages. Crit. Rev. Biotechnol. 22:89-174.

Uchida, M., and K. Kurakazu. 2004. Yogurt containing Lactobacillus gasseri OLL2716 exerts gastroprotective action against acute gastric lesions and antral ulcer in rats. J. Pharmacol. Sci. 96:8490.

Vaningelgem, F., M. Zamfir, F. Mozzi, T. Adriany, M. Vancanneyt, J. Swings, and L. De Vuyst. 2004. Biodiversity of exopolysaccharides produced by Streptococcus thermophilus strains is reflected in their production and their molecular and functional characteristics. Appl. Environ. Microbiol. 70:900-912.

Vinderola, C. G., J. Duarte, D. Thangavel, G. Perdigón, E. Farnworth, and C. Matar. 2005. Immunomodulating capacity of kefir. J. Dairy Res. 72:195-202

Vinderola, C. G., M. Medici, and G. Perdigón. 2004. Relationship between interaction sites in the gut, hydrophobicity, mucosal immunomodulating capacities and cell wall protein profiles in indigenous and exogenous bacteria. J. Appl. Microbiol. 96:230243.

Wallace, J. L. 1997. Nonsteroidal anti-inflammatory drugs and gastroenteropathy: The second hundred years. Gastroenterology 112:1000-1016.

Wallace, J. L., G. W. McKnight, and C. J. Bell. 1995. Adaptation of rat gastric mucosa to aspirin requires mucosal contact. Am. J. Physiol. 268:G134-G138.

Weinbreck, F., R. de Vries, P. Schrooyen, and C. G. de Kruif. 2003. Complex coacervation of whey proteins gum arabic. Biomacromolecules 4:293-303.

Yamada, H. 1995. Structure and pharmacological activity of peptic polysaccharides from the roots of Bupleurum falcatum L. Nippon Yakurigaku Zasshi 106:229-237.

Yamamoto, T., M. Kita, T. Ohno, Y. Iwakura, K. Sekikawa, and J. Imanishi. 2004. Role of tumor necrosis factor-alpha and interferongamma in Helicobacter pylori infection. Microbiol. Immunol. 48:647-654. 